\title{
Silício na nutrição mineral e acúmulo de alumínio em plantas de arroz de terras altas ${ }^{1}$
}

\author{
Lucas Barbosa de Freitas ${ }^{2}$, Dirceu Maximino Fernandes ${ }^{2}$, Suelen Cristina Mendonça Maia ${ }^{3}$
}

\begin{abstract}
Silicon on the mineral nutrition and

aluminum accumulation in upland rice plants

Silicon is able to protect plants against various biotic and abiotic stresses, including aluminum stress. However, the interaction between silicon and aluminum is still little known, since there are several hypotheses to justify the silicon role on aluminum stress alleviation. This study aimed at evaluating the effect of silicon application on contents and accumulation of macro and micronutrients, aluminum and silicon on shoots of upland rice grown under aluminum stress, as well as the chemical characteristics of the soil after harvest. The experimental design was randomized blocks, in a 2 x 5 factorial arrangement, with four replications. Treatments consisted of two upland rice cultivars (BRS Talento - aluminum non-tolerant; Guarani - aluminum tolerant) and five silicon doses $\left(0 \mathrm{mg} \mathrm{dm}^{-3}, 30 \mathrm{mg} \mathrm{dm}^{-3}, 60 \mathrm{mg} \mathrm{dm}^{-3}, 90 \mathrm{mg} \mathrm{dm}^{-3}\right.$ and $\left.120 \mathrm{mg} \mathrm{dm}^{-3}\right)$. The silicon applied increases the silicon content in the plant and soil and decreases the aluminum content in shoots, however, it does not increase the macro and micronutrients absorption and does not change the soil aluminum content and $\mathrm{pH}$.
\end{abstract}

KEY-WORDS: Oryza sativa; nitrogen; boron.

\section{INTRODUÇÃO}

O alumínio (Al) na solução do solo é tóxico às plantas, interrompendo ou diminuindo a divisão celular e, consequentemente, o crescimento radicular. Além disso, o Al também influencia negativamente os processos fisiológicos, como alterações na homeostase celular do cálcio e nas proteínas de transporte na membrana (Sun et al. 2010, Garzon et al. 2011, Guo et al. 2012).

O Al também pode provocar alterações na permeabilidade da membrana plasmática, influenciando a passagem de íons tanto para o interior quanto para o exterior das células e da planta (Kochian et al.

\section{RESUMO}

O silício é capaz de proteger as plantas contra vários estresses bióticos e abióticos, entre eles o estresse por alumínio. No entanto, a interação entre silício e alumínio ainda é pouco conhecida, sendo que há diversas hipóteses para justificar o papel do silício na amenização do estresse causado por alumínio. Objetivou-se avaliar o efeito da aplicação de silício nos teores e acúmulos de macro e micronutrientes, alumínio e silício na parte aérea de plantas de arroz de terras altas cultivadas sob estresse por alumínio, bem como as características químicas do solo após a colheita. O delineamento experimental utilizado foi o de blocos casualizados, disposto em modelo fatorial $2 \times 5$, com quatro repetições. Os tratamentos consistiram de duas cultivares de arroz de terras altas (BRS Talento - não tolerante ao alumínio; Guarani - tolerante ao alumínio) e cinco doses de silício $\left(0 \mathrm{mg} \mathrm{dm}^{-3}, 30 \mathrm{mg} \mathrm{dm}^{-3}, 60 \mathrm{mg} \mathrm{dm}^{-3}, 90 \mathrm{mg} \mathrm{dm}^{-3} \mathrm{e} 120 \mathrm{mg} \mathrm{dm}^{-3}\right)$. O silício aplicado aumenta o teor de silício na planta e no solo e diminui o teor de alumínio na parte aérea, porém, não incrementa a absorção de macro e micronutrientes e não altera o teor de alumínio e $\mathrm{pH}$ do solo.

PALAVRAS-CHAVE: Oryza sativa; nitrogênio; boro.

2004). Assim, sob essas ações negativas mediadas pelo Al, a eficiência de absorção de água e nutrientes das raízes é diminuída, especialmente em camadas mais profundas do solo (Mendonça et al. 2003, Sun et al. 2010).

Plantas de arroz de terras altas, apesar de serem consideradas tolerantes ao Al(Fageria 1998), quando expostas a solos com saturação por Al superior a $25 \%$ podem manifestar sintomas de toxidez (Embrapa 2007).

Além disso, plantas de arroz são altamente eficientes na absorção e acúmulo de silício ( $\mathrm{Si}$ ) em seus tecidos (Tokura et al. 2011). O Si é considerado um elemento benéfico, uma vez que é capaz de proteger

1. Trabalho recebido em out./2015 e aceito para publicação em dez./2015 (http://dx.doi.org/10.1590/1983-40632015v4538085).

2. Universidade Estadual Paulista “Júlio de Mesquita Filho", Faculdade de Ciências Agronômicas, Departamento de Solos e

Recursos Ambientais, Botucatu, SP, Brasil.E-mails: lucasbarbosaf@yahoo.com.br,dmfernandes@fca.unesp.br.

3. Instituto Federal Goiano, Câmpus Avançado Cristalina, Cristalina, GO, Brasil.E-mail: suelen.maia@ifgoiano.edu.br. 
as plantas contra estresses bióticos e abióticos ( Ma \& Yamaji 2006), entre eles o estresse por Al.

Freitas et al. (2012) observaram aumento na produtividade de grãos de cultivar de arroz de terras altas tolerante, mediante doses crescentes de Si e cultivo sob estresse por Al. Hara et al. (1999) demonstraram decréscimo no teor de Al na parte aérea e raiz de plantas de arroz, em tratamentos com aplicação de alta concentração de Si.

Nhan \& Hai (2013) citam a amenização da toxidez causada por Al em plântulas de arroz, com a aplicação de Si. Singh et al. (2011) também descreveram a atuação do Si no decréscimo da toxidez causada por Al, em plantas de arroz, bem como decréscimo no acúmulo de Al. Os benefícios do Si na amenização do estresse por Al são fundamentados em dois aspectos: solução do solo e mecanismos internos das plantas (Ma 2004). Hodson \& Sangster (1999) destacam que o efeito do Si na amenização do Al tóxico é resultado da diminuição na concentração de $\mathrm{Al}$ na solução do solo, por meio da formação de complexos Al-Si, aumentando a disponibilidade de nutrientes no solo.

No interior da planta, uma das hipóteses para explicar a menor toxidez por Al na presença de Si é a formação de compostos aluminossilicatos na parede celular do córtex da raiz, inibindo a movimentação do Al para o protoplasma. Com isso, o efeito tóxico causado pelo $\mathrm{Al}$ seria reduzido, otimizando a absorção de nutrientes como efeito indireto, devido à menor toxidez causada às raízes (Ma \& Yamaji 2006). Ainda, Ryder et al. (2003) citam que a amenização do estresse por $\mathrm{Al}$ por meio do $\mathrm{Si}$ ocorre devido à combinação das reações no solo e no interior da planta.

A interação entre $\mathrm{Si}$ e $\mathrm{Al}$ ainda é pouco conhecida, e há diversas hipóteses para explicar a amenização da toxidez por Al com $\mathrm{Si}$, mas nenhuma conclusiva. Também não há informação na literatura sobre o comportamento dos macro e micronutrientes na planta, quando há interação entre Si e Al. Portanto, objetivou-se avaliar o efeito da aplicação de Si nos teores e acúmulos de macro e micronutrientes, bem como de $\mathrm{Al} \mathrm{e} \mathrm{Si,} \mathrm{na} \mathrm{parte} \mathrm{aérea} \mathrm{de} \mathrm{plantas} \mathrm{de} \mathrm{arroz} \mathrm{de}$ terras altas cultivadas sob estresse por Al. Também foram avaliadas as características químicas do solo, após a colheita do experimento.

\section{MATERIAL E MÉTODOS}

O experimento foi conduzido em túnel plástico, na Faculdade de Ciências Agronômicas da Univer- sidade Estadual Paulista (Unesp), em Botucatu (SP) (48 $23^{\circ} \mathrm{W}, 22^{\circ} 51^{\prime} \mathrm{S}$ e $765 \mathrm{~m}$ de altitude). O solo utilizado apresentava as seguintes características químicas, antes da instalação do experimento: $\mathrm{P}=7 \mathrm{mg} \mathrm{dm}^{-3}$; matéria orgânica $=15 \mathrm{~g} \mathrm{dm}^{-3} ; \mathrm{pH}\left(\mathrm{CaCl}_{2}\right)=4,1 ; \mathrm{K}=$ $0,7 \mathrm{mmol}_{\mathrm{c}} \mathrm{dm}^{-3} ; \mathrm{Ca}=5 \mathrm{mmol}_{\mathrm{cm}} \mathrm{dm}^{-3} \mathrm{Mg}=3 \mathrm{mmol}_{\mathrm{c}} \mathrm{dm}^{-3}$; $\mathrm{H}+\mathrm{Al} \stackrel{\mathrm{c}}{=} 69 \mathrm{mmol}_{\mathrm{c}} \mathrm{dm}^{-3} ; \mathrm{Al}=11 \mathrm{mmol}_{\mathrm{c}}{ }^{\mathrm{c}} \mathrm{dm}^{-3}$; $\mathrm{CTC}=78 \mathrm{mmol}_{\mathrm{c}} \mathrm{dm}^{-3} ; \mathrm{Si}$ (cloreto de cálcio $0,01 \mathrm{M}$ ) = $2 \mathrm{mg} \mathrm{kg}^{-1} ; \mathrm{V}(\%)=11$. O solo foi classificado como Latossolo Vermelho-Escuro, com textura média arenosa, e alumínico $(\mathrm{m} \%=55)$.

$\mathrm{O}$ delineamento experimental utilizado foi o de blocos casualizados, em esquema fatorial $2 \times 5$, com quatro repetições. Os tratamentos foram duas cultivares de arroz de terras altas [BRS Talento - não tolerante a Al (Silva et al. 2011); Guarani - tolerante a $\mathrm{Al}$ (Ferreira et al. 1995)] e cinco doses de $\mathrm{Si}$ $\left(0 \mathrm{mg} \mathrm{dm}^{-3}, 30 \mathrm{mg} \mathrm{dm}^{-3}, 60 \mathrm{mg} \mathrm{dm}^{-3}, 90 \mathrm{mg} \mathrm{dm}^{-3} \mathrm{e}\right.$ $\left.120 \mathrm{mg} \mathrm{dm}^{-3}\right)$.

Os tratamentos foram aplicados após a semeadura, solubilizando o silicato de potássio $(25 \%$ de $\mathrm{Si}, 25 \%$ de $\mathrm{SiO}_{2}$ e $15 \%$ de $\mathrm{K}_{2} \mathrm{O}$ ) em água, sobre a superfície do solo. Porém, salienta-se que o potássio foi balanceado nas parcelas em que foi aplicado o silicato de potássio, com a adição de $\mathrm{KCl}$, até atingir a quantidade padronizada de $\mathrm{K}$ utilizada no experimento para todos os tratamentos. A adubação de semeadura consistiu de $100 \mathrm{mg} \mathrm{dm}^{-3}$ de $\mathrm{N}$ (ureia), $300 \mathrm{mg} \mathrm{dm}^{-3} \mathrm{de} \mathrm{P}$ (superfosfato triplo) e $150 \mathrm{mg} \mathrm{dm}^{-3}$ de K (cloreto de potássio).

Utilizaram-se vasos com capacidade para 40 litros de solo. A semeadura foi realizada no dia 08 de janeiro de 2010, utilizando-se 100 sementes em uma linha de $0,40 \mathrm{~m}$ por vaso. Verificou-se emergência aos 6 e 8 dias após a semeadura (DAS), respectivamente para as cultivares Guarani e BRS Talento. Após a emergência das plantas, foi realizado desbaste, com o objetivo de manter 30 plantas por vaso.

O florescimento das cultivares ocorreu aos 83 DAS (Guarani) e 101 DAS (BRS Talento). Nessa época, foram coletadas 50 folhas-bandeiras em cada unidade experimental, para determinação do teor de nitrogênio $(\mathrm{N})$, fósforo $(\mathrm{P})$, potássio $(\mathrm{K})$, cálcio $(\mathrm{Ca})$, magnésio $(\mathrm{Mg})$, enxofre $(\mathrm{S})$, boro $(\mathrm{B})$, cobre $(\mathrm{Cu})$, ferro $(\mathrm{Fe})$, manganês $(\mathrm{Mn})$, zinco $(\mathrm{Zn})$ e $\mathrm{Al}$ (Malavolta et al. 1997). O teor de Si foi determinado de acordo com Korndörfer (2004).

Foi realizada a colheita aos 111 (Guarani) e 138 DAS (BRS Talento). Nesse momento, a massa verde (sem os grãos) foi coletada e pesada e, em seguida, 
foram retiradas subamostras, as quais também foram pesadas. As subamostras foram levadas a estufa com circulação forçada de ar, a $65^{\circ} \mathrm{C}$, até adquirirem peso constante. Posteriormente, foi determinada a produção de massa seca na subamostra e estimada para a massa seca total do vaso. A subamostra foi moída e avaliada quimicamente, para determinação dos teores de N, P, K, Ca, Mg, S, Cu, Fe, Mn, Zn, B e Al. Os dados referentes à produção de massa seca da parte aérea foram apresentados em Freitas et al. (2012).

Os teores obtidos para massa seca, no fim do ciclo da cultura, foram utilizados para o cálculo do

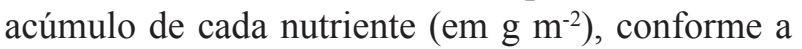
seguinte equação:

$$
\text { Acúmulo de nutrientes }=\frac{\mathrm{C} \times \mathrm{MS}}{1.000}
$$

sendo $C$ a concentração do nutriente presente na amostra e $M S$ a massa seca da amostra.

Após a colheita, foram obtidas amostras de solo para análises de $\mathrm{pH}$, teor de matéria orgânica (MO), soma de bases (SB), capacidade de troca de cátions (CTC), saturação de bases (V\%) e os teores de P, K, Ca, Mg, S, Cu, Fe, Mn, Zn, B, Al e Si.

Os resultados obtidos foram submetidos à análise de variância, pelo teste $\mathrm{F}$. As cultivares foram comparadas pelo teste $\mathrm{t}$ (DMS), a $5 \%$, enquanto os efeitos das doses de Si foram avaliados por meio de análise de regressão. Com o objetivo de diferenciar o comportamento das cultivares, nas interações, utilizou-se o método estatístico "não protegido" (Vieira 1999). Dessa forma, os modelos foram escolhidos baseando-se na significância da regressão pelo teste $\mathrm{F}(\mathrm{p}<0,05)$ e no coeficiente de determinação.

\section{RESULTADOS E DISCUSSÃO}

A aplicação de Si não influenciou os teores de macronutrientes na folha-bandeira das cultivares submetidas ao estresse por Al (dados não mostrados). As médias gerais dos teores de macronutrientes nos tratamentos (doses de $\mathrm{Si}$ ) se encontram na Tabela 1. Mesmo com o alto teor inicial de Al no solo $\left(11 \mathrm{mmol}_{\mathrm{c}} \mathrm{dm}^{-3}\right)$, todos os macronutrientes se encontravam dentro da faixa adequada, segundo Fageria (1984).

Entre os micronutrientes, somente o teor de $\mathrm{B}$ na folha-bandeira da cultivar BRS Talento foi influenciado pela aplicação de $\mathrm{Si}$, apresentando comportamento linear decrescente (Figura 1a). Esse resultado pode ter ocorrido devido às similaridades químicas do ácido silícico e do ácido bórico em solução. Além disso, o B participa da síntese e estruturação da parede celular e apresenta demanda inversamente proporcional à capacidade de absorver Si (Marschner 1995). Gunes et al. (2007) citam que o Si pode reduzir a toxidez por B. Mesmo não havendo toxidez por B nas condições do experimento, o Si pode ter diminuído o transporte de B para a parte aérea.

O teor de Si na folha-bandeira foi influenciado em ambas as cultivares pela aplicação de Si (Figura 1b), corroborando Mauad et al. (2003) e Reis et al. (2008). O Si influenciou o teor de Al na folha-bandeira, diminuindo-o (Figura 1c).

Como o principal sintoma causado pelo estresse por Al é o decréscimo na absorção de nutrientes (Kochian et al. 2004), esperava-se que, com o decréscimo no teor de Al na parte aérea das plantas, houvesse aumento nos teores de macro e micronutrientes na mesma. No entanto, esse efeito não foi observado.

Os teores de Si na parte aérea (folha + colmo) estão próximos aos citados por Currie \& Perry (2007), que consideram valores adequados para $\mathrm{Si}$ de $10-20 \mathrm{~g} \mathrm{~kg}^{-1}$. Ao comparar as duas cultivares, a BRS Talento apresentou maior teor de Si (Tabela 1). As diferenças genotípicas entre as cultivares, em

Tabela 1. Médias gerais dos teores de nitrogênio, fósforo, potássio, cálcio, magnésio, enxofre, silício, boro, cobre, manganês, ferro, zinco e alumínio na folha-bandeira das plantas, no momento do florescimento das cutivares de arroz Guarani e BRS Talento (Botucatu, SP, 2010).

\begin{tabular}{|c|c|c|c|c|c|c|c|c|c|c|c|c|c|}
\hline \multirow{2}{*}{ Cultivares } & $\mathrm{N}$ & $\mathrm{P}$ & $\mathrm{K}$ & $\mathrm{Ca}$ & $\mathrm{Mg}$ & S & $\mathrm{Si}$ & B & $\mathrm{Cu}$ & $\mathrm{Mn}$ & $\mathrm{Fe}$ & $\mathrm{Zn}$ & Al \\
\hline & \multicolumn{7}{|c|}{$-\mathrm{g} \mathrm{kg}^{-1}$} & \multicolumn{6}{|c|}{$\mathrm{mg} \mathrm{kg}^{-1}$} \\
\hline Guarani & 27,55 & $2,26 \mathrm{~b}$ & $10,05 \mathrm{~b}$ & 5,90 & $3,10 \mathrm{a}$ & $2,09 \mathrm{~b}$ & $11,35 \mathrm{~b}$ & $23,80 \mathrm{~b}$ & $8,65 \mathrm{a}$ & 138,30 & $54,15 \mathrm{~b}$ & $24,65 \mathrm{a}$ & $41,90 \mathrm{a}$ \\
\hline$\underline{\text { BRS Talento }}$ & 27,01 & $3,75 \mathrm{a}$ & $11,20 \mathrm{a}$ & 6,30 & $1,50 \mathrm{~b}$ & $2,32 \mathrm{a}$ & $13,39 \mathrm{a}$ & $31,05 \mathrm{a}$ & $7,30 \mathrm{~b}$ & 112,70 & $71,40 \mathrm{a}$ & $16,00 \mathrm{~b}$ & $36,15 \mathrm{~b}$ \\
\hline $\mathrm{CV}(\%)$ & 6,60 & 8,20 & 12,40 & 14,20 & 10,40 & 8,30 & 13,40 & 12,40 & 13,00 & 46,20 & 11,50 & 26,90 & 5,50 \\
\hline
\end{tabular}

Médias seguidas de letras diferentes, dentro de cada parâmetro, diferem entre si pelo teste $\mathrm{F}(\mathrm{p}<0,05)$. 
resposta ao $\mathrm{Si}$, podem ser atribuídas a mecanismos fisiológicos, como diferentes taxas de absorção e translocação de nutrientes, bem como devido a
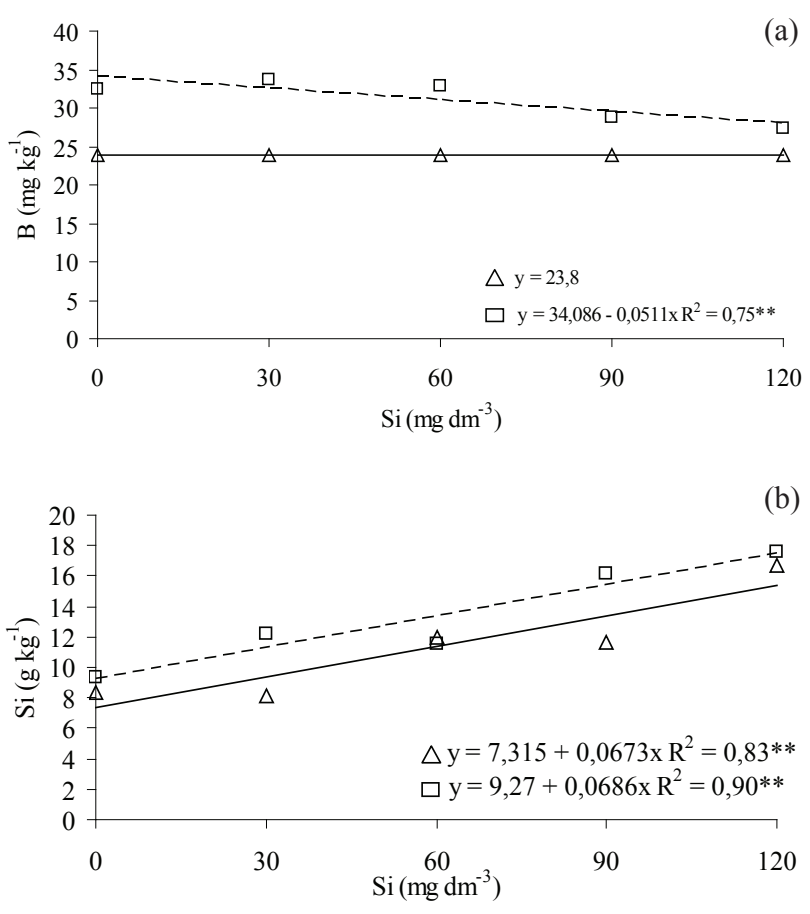

(c)

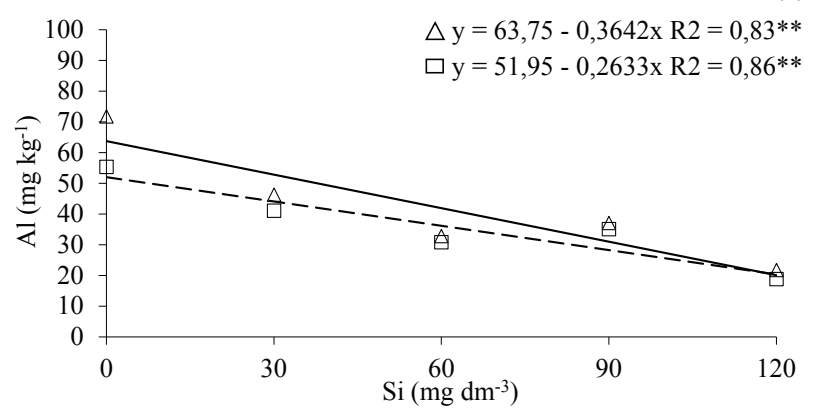

Figura 1. Teores de boro (a), silício (b) e alumínio (c) na folhabandeira das cultivares de arroz Guarani $(\Delta)$ e BRS Talento ( $\square$ ), em função das doses de silício (Botucatu, SP, 2010). ${ }^{* *} \mathrm{p}<0,01$. diferenças morfológicas no sistema radicular (Faria Junior et al. 2009).

O teor (Tabela 1) e acúmulo (Tabela 2) de Al foram diferentes entre as cultivares. A cultivar Guarani apresentou maior teor e acúmulo desse elemento na planta. Isso demonstra que a cultivar tolerante ao $\mathrm{Al} \mathrm{acu-}$ mula maior quantidade de $\mathrm{Al}$, sendo provável que tenha mecanismo interno de tolerância (Kochian et al. 2004).

$\mathrm{Na}$ média dos tratamentos, o acúmulo de nutrientes e elementos na parte aérea das plantas obedeceu à seguinte ordem decrescente: $\mathrm{Si}>\mathrm{K}>$ $\mathrm{N}>\mathrm{Ca}>\mathrm{Mg}>\mathrm{S}>\mathrm{P}>\mathrm{Al}>\mathrm{Fe}>\mathrm{Mn}>\mathrm{Zn}>\mathrm{B}>\mathrm{Cu}$ (cultivar Guarani) e $\mathrm{K}>\mathrm{Si}>\mathrm{N}>\mathrm{Ca}>\mathrm{Mg}>\mathrm{S}>\mathrm{P}>$ $\mathrm{Al}>\mathrm{Mn}>\mathrm{Fe}>\mathrm{B}>\mathrm{Zn}>\mathrm{Cu}$ (cultivar BRS Talento). Assim, na presença de Al no solo, houve diferença entre as cultivares, sendo que a Guarani acumulou mais Si na massa seca do que a BRS Talento (Tabela 2).

Esses resultados estão de acordo com os obtidos por Tokura et al. (2011), os quais citam que o Si é o elemento absorvido em maior quantidade por plantas de arroz. Isso ocorre, provavelmente, devido à alta densidade de transportadores de Si no sistema radicular dessas plantas (Mitani \& Ma 2005, Ma et al. 2006).

Além da alta absorção do elemento benéfico Si por plantas de arroz de terras altas, Crusciol et al. (2003) citam o K e o N como os nutrientes mais requeridos pela cultura. Dessa forma, justifica-se o K como maior "nutriente" acumulado na parte aérea das plantas (Tabela 2).

$\mathrm{O}$ acúmulo de $\mathrm{N}$ na massa seca da parte aérea foi influenciado de forma negativa pela aplicação de Si apenas para a cultivar BRS Talento (Figura 2a). Há possibilidade de que tenha ocorrido interação entre o $\mathrm{N}$ e o $\mathrm{Si}$, ou seja, entre o $\mathrm{H}_{3} \mathrm{SiO}_{4}$ e o $\mathrm{NO}_{3}^{-}$. Essas moléculas concorrem pelo mesmo transportador (Wallace 1989), o que pode ter ocasionado a diminuição no acúmulo de $\mathrm{N}$ na parte aérea, com o aumento da dose de Si aplicada.

Tabela 2. Médias gerais de acúmulo de nitrogênio, fósforo, potássio, cálcio, magnésio, enxofre, silício, boro, cobre, manganês, ferro, zinco e alumínio das plantas após a colheita das cutivares de arroz Guarani e BRS Talento (Botucatu, SP, 2010).

\begin{tabular}{|c|c|c|c|c|c|c|c|c|c|c|c|c|c|}
\hline \multirow{2}{*}{ Cultivares } & $\mathrm{N}$ & $\mathrm{P}$ & $\mathrm{K}$ & $\mathrm{Ca}$ & $\mathrm{Mg}$ & S & $\mathrm{Si}$ & $\mathrm{B}$ & $\mathrm{Cu}$ & $\mathrm{Mn}$ & $\mathrm{Fe}$ & $\mathrm{Zn}$ & $\mathrm{Al}$ \\
\hline & \multicolumn{7}{|c|}{$\mathrm{g} \mathrm{m}^{-2}$} & \multicolumn{6}{|c|}{$\mathrm{mg} \mathrm{m}^{-2}$} \\
\hline Guarani & 12,17 & 2,93 & 38,77 & 11,56 & $7,40 \mathrm{a}$ & $3,04 \mathrm{~b}$ & 39,89 a & $40,25 \mathrm{~b}$ & $9,37 \mathrm{a}$ & 442,59 & 426,29 & \multicolumn{2}{|c|}{68,04 a 671,9 a } \\
\hline BRS Talento & 13,17 & 3,32 & 36,55 & 11,45 & $6,16 b$ & $3,76 \mathrm{a}$ & $26,08 \mathrm{~b}$ & $54,74 \mathrm{a}$ & $7,35 \mathrm{~b}$ & 461,07 & 377,90 & \multicolumn{2}{|c|}{53,59 b 569,8 b } \\
\hline $\mathrm{CV}(\%)$ & 22,10 & 32,00 & 12,00 & 19,40 & 15,30 & 9,60 & 16,40 & 12,70 & 36,10 & 25,90 & 54,30 & 22,80 & 8,40 \\
\hline
\end{tabular}


Por outro lado, pode ter ocorrido interação entre $\mathrm{B}$ e $\mathrm{N}$, evidenciada pela diminuição do teor e acúmulo de $\mathrm{B}$ na parte aérea, com a aplicação de $\mathrm{Si}$ (Figura 1a). O B pode atuar na redução do nitrato e nos conteúdos de aminoácidos e proteínas, que poderiam ser maiores ou menores em plantas deficientes, dependendo da severidade da deficiência, idade e órgão da planta. Entretanto, não há, ainda, evidências concretas do efeito direto do B no metabolismo do $\mathrm{N}$, mas há indícios de que o $\mathrm{B}$ exerce mudanças secundárias que afetam a demanda por $\mathrm{N}$ na planta (Marschner 1995).

Ainda, sabe-se que o B participa de processos que envolvem compostos nitrogenados na síntese proteica (Dugger 1983). Portanto, o decréscimo de $\mathrm{B}$, com a aplicação de $\mathrm{Si}$, pode ter prejudicado a absorção de N pelas plantas. Mauad et al. (2003), trabalhando com doses de $\mathrm{N}$ e Si em arroz de sequeiro, observaram que os teores de Si na planta decrescem conforme aumentam as doses de nitrogênio em cobertura. No entanto, Ávila et al. (2010) obtiveram aumento no acúmulo de Si na parte aérea de plantas de arroz, com a aplicação de N.

$\mathrm{O}$ acúmulo de $\mathrm{K}$ na parte aérea da cultivar BRS Talento foi significativo, quando se aplicou $\mathrm{Si}$ (Figura 2b). Por outro lado, ao aumentar a concen- tração do Si aplicado, houve decréscimo no acúmulo de Ca (Figura 2c). De acordo com Marschner (1995), existe uma relação inversa entre a necessidade de $\mathrm{Ca}$ pelas plantas e a habilidade dessas em absorver o Si. Assim, o Ca poderia ter sua função afetada pela presença do Si. O Ca participa da formação e estruturação da parede celular, pela sua ligação com grupos R-COO- de ácidos poligalacturônicos (pectinas) da lamela média (Marschner 1995).

Já o acúmulo de $\mathrm{P}, \mathrm{Mg}$ e $\mathrm{S}$ não foram influenciados pela aplicação de $\mathrm{Si}$, e as médias para cada cultivar se encontram na Tabela 2.

$\mathrm{O}$ acúmulo de Si na parte aérea foi influenciado pela aplicação de Si ao solo (Figura 2d), assim como ocorreu com o teor de Si na folha-bandeira (Figura 1b). Com o aumento das doses de Si no solo, há acúmulo crescente de Si na parte aérea de ambas as cultivares (Figura $2 \mathrm{~d}$ ).

Houve influência da aplicação de Si no acúmulo de Al na parte aérea apenas para a cultivar BRS Talento (Figura 3e). Ao se aumentar a dose de Si aplicada ao solo, inicialmente, ocorreu uma queda no acúmulo de $\mathrm{Al}$ na parte aérea até $449 \mathrm{mg} \mathrm{m}^{-2}$. Contudo, com o aumento nas doses de $\mathrm{Si}$, o acúmulo de $\mathrm{Al}$ aumentou novamente. Porém, o acúmulo de $\mathrm{Al}$ não pode ser relacionado somente ao acúmulo de $\mathrm{Si}$,
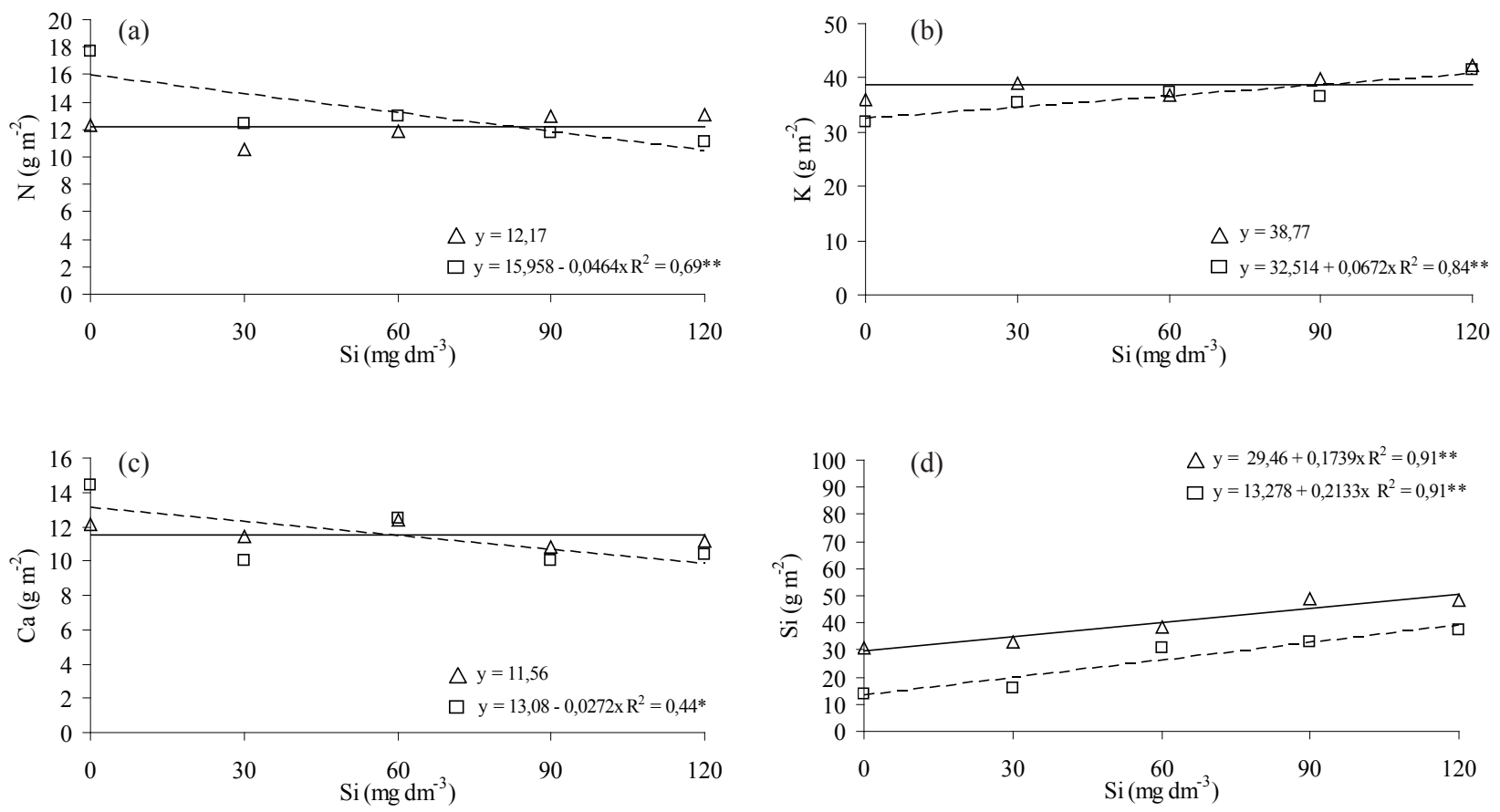

Figura 2. Acúmulo de nitrogênio (a), potássio (b), cálcio (c) e silício (d) na parte aérea das cultivares de arroz Guarani $(\Delta)$ e BRS Talento ( $\square$ ), em função das doses de silício (Botucatu, SP, 2010). * p <0,05;** p $<0,01$. 
como aconteceu para o teor de Si e Al na parte aérea (Figuras 1b e 1c).

Quanto ao acúmulo dos micronutrientes $\mathrm{Fe}$ e Mn, houve influência significativa somente para a cultivar BRS Talento, apresentando comportamento linear decrescente (Figuras 3c e 3d), enquanto, para o $\mathrm{Cu}$, ocorreu o mesmo comportamento para ambas as cultivares (Figura 3b). O Cu, Fe e Mn poderiam ter sido influenciados pelo aumento no $\mathrm{pH}$ do solo, já que, com o aumento do $\mathrm{pH}$, o teor disponível desses micronutrientes no solo diminui (Souza et al. 2007). Porém, isso não foi o observado, porque a fonte de Si utilizada não alterou o pH do solo (média apresentada na Tabela 3).

Ainda com relação ao $\mathrm{Fe}$ e $\mathrm{Mn}$, o Si pode diminuir a toxidez por Fe e Mn, em plantas de arroz
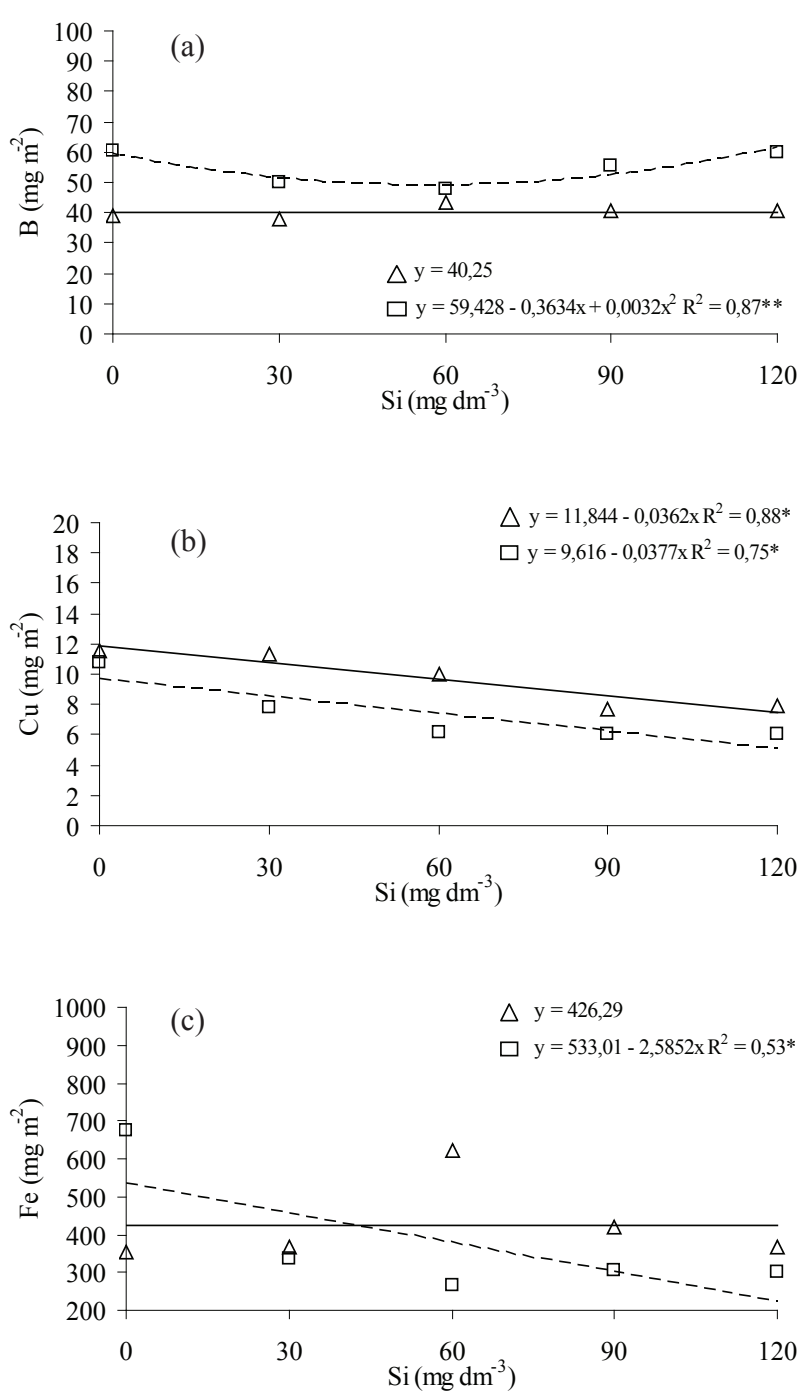

(Liang et al. 2007). Mesmo não ocorrendo toxidez por esses micronutrientes no experimento, pode ser que, com a aplicação de $\mathrm{Si}$, tenha sido diminuída a absorção de Fe e Mn.

Houve diferença para o acúmulo de $\mathrm{B}$ na parte aérea da cultivar BRS Talento (Figura 3a), obtendo-se comportamento quadrático, no qual houve, inicialmente, decréscimo no acúmulo de $\mathrm{B}$ até $47,87 \mathrm{mg} \mathrm{m}^{-2}$ e posterior aumento. Quanto ao acúmulo de Zn, esse não foi influenciado pela aplicação de Si ao solo (as médias para cada cultivar encontram-se na Tabela 2).

As características químicas do solo, $\mathrm{pH}, \mathrm{SB}$, CTC e V\% não foram influenciadas pela aplicação de Si. As médias dos atributos químicos do solo sob cada cultivar encontram-se na Tabela 3. O pH do solo não foi influenciado pela aplicação de $\mathrm{Si}$, mesmo com o íon Si tendo a capacidade de alterar o $\mathrm{pH}$ do solo. A reação do $\mathrm{SiO}_{3}^{-2}$, formando $\mathrm{H}_{2} \mathrm{SiO}_{3}^{-}$(Prado et al. 2003), poderia reduzir a concentração do $\mathrm{H}^{+}$presente na solução do solo (Ramos et al. 2012). No entanto, a não alteração de $\mathrm{pH}$ observada neste experimento está de acordo com Camargo et al. (2007). Esses autores demonstraram que o ácido silícico não foi capaz de alterar o pH do solo, mesmo em doses crescentes.

O Si aplicado não influenciou os teores de nutrientes e $\mathrm{Al}$ do solo, entre eles $\mathrm{K}, \mathrm{Ca}$ e $\mathrm{Mg}$.
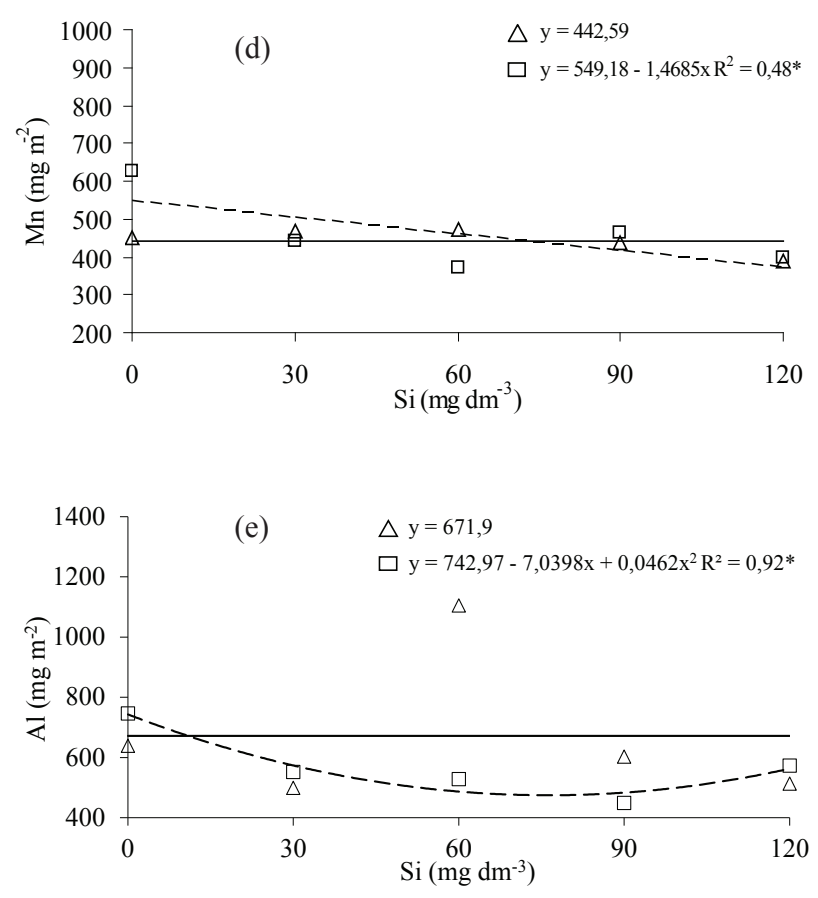

Figura 3. Acúmulo de boro (a), cobre (b), ferro (c), manganês (d) e alumínio (e) na parte aérea das cultivares de arroz Guarani ( $\Delta$ ) e BRS Talento ( $\square$ ), em função das doses de silício (Botucatu, SP, 2010). * p < 0,05; ** p $<0,01$. 
Tabela 3. Médias gerais de pH, matéria orgânica, fósforo, alumínio, hidrogênio + alumínio, potássio, cálcio, magnésio, soma de bases, capacidade de troca de cátions e saturação por bases e teores de boro, cobre, manganês, ferro e zinco do solo, após a colheita das cutivares de arroz Guarani e BRS Talento (Botucatu, SP, 2010).

\begin{tabular}{|c|c|c|c|c|c|c|c|c|c|c|c|c|c|c|c|c|}
\hline \multirow{2}{*}{ Cultivares } & $\mathrm{pH}$ & $\mathrm{MO}$ & P-resina & $\mathrm{Al}$ & $\mathrm{H}+\mathrm{Al}$ & $\mathrm{K}$ & $\mathrm{Ca}$ & $\mathrm{Mg}$ & SB & $\mathrm{CTC}$ & \multirow{2}{*}{$\begin{array}{c}\mathrm{V} \\
\%\end{array}$} & B & $\mathrm{Cu}$ & $\mathrm{Mn}$ & $\mathrm{Fe}$ & $\mathrm{Zn}$ \\
\hline & $\mathrm{CaCl}_{2}$ & $\mathrm{~g} \mathrm{dm}^{-3}$ & $\mathrm{mg} \mathrm{dm}^{-3}$ & & & $-\mathrm{mr}$ & lolc dm & & & & & \multicolumn{5}{|c|}{$\mathrm{mg} \mathrm{dm}^{-3}$} \\
\hline Guarani & 4,15 & 23,55 & 112,65 & 9,85 & 71,90 & 0,53 & 10,05 & 1,15 & 11,75 & 83,70 & 14,10 & 0,18 & 1,27 & 0,20 & 72,80 & 0,13 \\
\hline BRS Talento & 4,17 & 22,65 & 101,55 & 9,85 & 71,30 & 0,63 & 8,80 & 1,00 & 10,50 & 81,95 & 12,85 & 0,18 & 1,30 & 0,18 & 74,35 & 0,13 \\
\hline$\overline{\mathrm{CV}(\%)}$ & 2,00 & 15,40 & 21,00 & 16,50 & 7,30 & 26,90 & 22,90 & 22,40 & 20,70 & 5,30 & 22,40 & 12,20 & 4,60 & 35,20 & 9,90 & 26,80 \\
\hline
\end{tabular}

As médias da concentração desses elementos no solo, com cada cultivar, encontram-se na Tabela 3. Esperava-se decréscimo no teor de Al no solo, com a aplicação de $\mathrm{Si}$, pois poderia haver interação com $\mathrm{o} \mathrm{Al}$, transformando-o em composto não solúvel denominado hidroxialuminosilicato (HAS) (Hodson \& Sangster 1999). Porém, esse efeito não foi observado. Ma et al. (1997) e Wang et al. (2004), trabalhando com plantas de milho, observaram a formação de HAS provenientes da interação entre Si e Al, forma esta inativa, não causando toxidez.

Devido ao não decréscimo no teor de $\mathrm{Al}$ do solo, pode-se concluir que não houve interação entre $\mathrm{Al}$ e Si no solo em estudo, como previsto por Hodson \& Sangster (1999). Provavelmente, a interação entre $\mathrm{Si}$ e $\mathrm{Al}$ se deu somente no interior das plantas, devido ao fato de o teor de $\mathrm{Al}$ na parte aérea ter se reduzido com a aplicação de $\mathrm{Si}$ (Figuras $1 \mathrm{~b}$ e 1c), reforçando a hipótese citada por Ma \& Yamaji (2006).

$\mathrm{O}$ teor de Si no solo após a colheita aumentou com a aplicação de Si (Figura 4), o que pode justificar o aumento do teor de Si na parte aérea das plantas (Figura 1b), e com o decréscimo do teor de Al nas cultivares avaliadas (Figura 1c). Esse resultado reforça a hipótese de que houve interação Si-Al somente

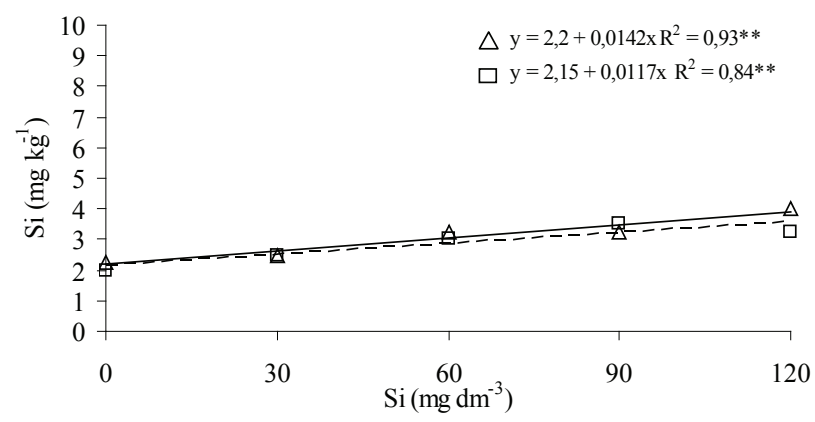

Figura 4. Teor de silício no solo após o cultivo de arroz Guarani $(\Delta)$ e BRS Talento $(\square)$, em função de doses de silício (Botucatu, SP, 2010). ** $\mathrm{p}<0,01$. na parte aérea das plantas. O teor de $\mathrm{Si}$ aumentou, porém, atingindo o máximo de $4 \mathrm{mg} \mathrm{kg}^{-1}$, teor esse considerado baixo, segundo Korndörfer et al. (2001).

$\mathrm{O}$ baixo teor de Si inicial do solo $\left(2 \mathrm{mg} \mathrm{kg}^{-1}\right)$ é consequência do avançado grau de intemperismo em que se encontram os solos de regiões tropicais (Korndörfer et al. 1999) e dos elevados teores de sesquióxidos de $\mathrm{Al} \mathrm{e} \mathrm{Fe,} \mathrm{que} \mathrm{são} \mathrm{os} \mathrm{principais} \mathrm{responsáveis} \mathrm{pela} \mathrm{ad-}$ sorção de Si em solução (Savant et al. 1997). Com isso, pode-se inferir que o aumento no teor de Si do solo após a colheita, apesar de ter ocorrido (Figura 4), foi mínimo. $\mathrm{Na}$ dose de $120 \mathrm{mg} \mathrm{dm}^{-3} \mathrm{de} \mathrm{Si}$, o teor desse elemento foi elevado de $2 \mathrm{mg} \mathrm{kg}^{-1}$ (antes do experimento) para $3,90 \mathrm{mg} \mathrm{kg}^{-1}$ e 3,55 $\mathrm{mg} \mathrm{kg}^{-1}$ (após a colheita), respectivamente para as cultivares Guarani e BRS Talento.

É relevante citar que a cultivar Guarani foi eficiente em acumular Si na parte aérea, pois o teor inicial disponível de Si no solo era de $2 \mathrm{mg} \mathrm{dm}^{-3}$, ou seja, $0,08 \mathrm{~g}$ em todo o volume de solo do vaso. Com a aplicação de $120 \mathrm{mg} \mathrm{dm}^{-3} \mathrm{de} \mathrm{Si}$, iniciou-se o experimento com 4,88 g de $\mathrm{Si}$ no solo do vaso e, ao final do experimento, restaram somente $0,15 \mathrm{~g}$ de Si nos vasos com a cultivar Guarani. Esses valores evidenciam a alta extração de Si pelas plantas de arroz (Mitani \& Ma 2005, Ma et al. 2006), pois, mesmo com a adição de $\mathrm{Si}$, o teor final desse elemento no solo foi baixo. Dessa forma, mesmo em solos com alta concentração de $\mathrm{Al}$, observa-se alta eficiência de extração de Si pelas plantas de arroz.

Os micronutrientes do solo não foram influenciados pela aplicação de $\mathrm{Si}$, e suas médias, para cada cultivar, encontram-se na Tabela 3. Ressalta-se que algumas interações entre Si e micronutrientes ocorreram na planta, especialmente para o B, Fe e Mn.

\section{CONCLUSÕES}

1. O Si aplicado aumenta o teor de Si no solo e na planta e diminui o teor de $\mathrm{Al}$ na parte aérea das plantas de ambas as cultivares. 
2. Apesar da interação entre Si e Al, não há incremento na absorção de nenhum macro e micronutriente.

3. A aplicação de silicato de potássio não altera a disponibilidade de nutrientes, $\mathrm{Al}$ e $\mathrm{pH}$ do solo. Dessa forma, não há evidência de interação entre Si e Al no solo em estudo. Tal interação ocorre somente após os elementos serem absorvidos pelas plantas.

\section{AGRADECIMENTOS}

À Fundação de Amparo à Pesquisa do Estado de São Paulo (FAPESP), pelo apoio financeiro concedido por meio de bolsa de mestrado (Processo ${ }^{\circ}$ 2009/03351-3) e projeto de auxílio regular à pesquisa (Processo $\mathrm{n}^{\circ}$ 2009/15258-8).

\section{REFERÊNCIAS}

ÁVILA, F. W. et al. Interação entre silício e nitrogênio em arroz cultivado sob solução nutritiva. Revista Ciência Agronômica, Fortaleza, v. 41, n. 2, p. 184-190, 2010.

CAMARGO, M. S. et al. Soil reaction and absorption of silicon by rice. Scientia Agricola, Piracicaba, v. 64, n. 2 , p. 176-180, 2007.

CURRIE, H. A.; PERRY, C. Silica in plants: biological, biochemical and chemical studies. Annals of Botany, Oxford, v. 100, n. 7, p. 1-7, 2007.

CRUSCIOL, C. A. C. et al. Extração de macronutrientes pelo arroz de terras altas sob diferentes níveis de irrigação por aspersão e de adubação. Revista Brasileira de Agrociência, Pelotas, v. 9, n. 2, p. 145-150, 2003.

DUGGER, W. M. Boron in plant metabolism. In: LÄUCHLI, A.; BIELISKI, R. L. (Eds.). Inorganic plant nutrition. Berlin: Springer-Verlag, 1983. p. 623-650.

EMPRESA BRASILEIRA DE PESQUISA AGROPECUÁRIA (Embrapa). Informações técnicas sobre o arroz de terras altas: Estados de Mato Grosso e Rondônia, safra 2007/2008. Santo Antônio de Goiás: Embrapa Arroz e Feijão, 2007. (Documentos, 212).

FAGERIA, N. K. Adubação e nutrição mineral da cultura de arroz. Goiânia: Embrapa, 1984.

FAGERIA, N. K. Otimização da eficiência nutricional na produção das culturas. Revista Brasileira de Engenharia Agrícola e Ambiental, Campina Grande, v. 2, n. 1, p. 6-16, 1998.

FARIA JUNIOR, L. A. et al. Produção de massa seca, teor e acúmulo de silício em cultivares de arroz sob doses de silício. Ciência e Agrotecnologia, Lavras, v. 33, n. 4, p. 1034-1040, 2009.
FERREIRA, R. P. et al. Identificação de cultivares de arroz tolerantes à toxidez de alumínio por técnica multivariada. Pesquisa Agropecuária Brasileira, Brasília, DF, v. 30, n. 6, p. 789-795, 1995.

FREITAS, L. B.; FERNANDES, D. M.; MAIA, S. C. M. Interação silício e alumínio em plantas de arroz de terras altas cultivadas em solo alumínico. Revista Brasileira de Ciência do solo, Viçosa, v. 36, n. 2, p. 507-516, 2012.

GARZON, T. et al. Aluminum-induced alteration of ion homeostasis in root tip vacuoles of two maize varieties differing in Al tolerance. Plant Science, New York, v. 180, n. 5, p. 709-715, 2011.

GUNES, A. et al. Silicon increases boron tolerance and reduces oxidative damage of wheat grown in soil with excess boron. Biologia Plantarum, Praha, v. 51, n. 3, p. 571-574, 2007.

GUO, T. R. et al. Involvement of antioxidative defense system in rice growing seedlings exposed to aluminum toxicity and phosphorus deficiency. Rice Science, New York, v. 19, n. 3, p. 207-212, 2012.

HARA, T.; GU, M-H.; KOYAMA, H. Ameliorative effect of silicon on aluminum injury in the rice plant. Soil Science and Plant Nutrition, Tokyo, v. 45, n. 4, p. 929-936, 1999.

HODSON, M. J.; SANGSTER, A. G. Aluminum/silicon interactions in conifers. Journal of Inorganic Biochemistry, Chicago, v. 76, n. 2, p. 89-98, 1999.

KOCHIAN, L. V.; HOEKENGA, O. A.; PIÑEROS, M. A. How do crop plants tolerate acid soils?: mechanisms of aluminum tolerance and phosphorous efficiency. Annual Review of Plant Physiology and Molecular Biology, Palo Alto, v. 55, n. 1, p. 459-493, 2004.

KORNDÖRFER, G. H. Análise de silício: solo, planta e fertilizante. Uberlândia: GPSi-ICIAG-UFU, 2004. (Boletim técnico, 2).

KORNDÖRFER, G. H. et al. Calibration of soil and plant silicon analysis for rice production. Journal of Plant Nutrition, New York, v. 24, n. 7, p. 1071-1084, 2001.

KORNDÖRFER, G. H. et al. Efeito do silicato de cálcio no teor de silício e na produção de grãos de arroz de sequeiro. Revista Brasileira de Ciência do Solo, Viçosa, v. 23, n. 3, p. 635-41, 1999.

LIANG, Y. et al. Mechanisms of silicon-mediated alleviation of abiotic stresses in higher plants: a review. Environmental Pollution, Boston, v. 147, n. 2, p. 422-428, 2007.

MA, J. F. Role of silicon in enhancing the resistance of plants to biotic and abiotic stresses. Soil Science \& Plant Nutrition, Tokyo, v. 50, n. 1, p. 11-18, 2004. 
MA, J. F. et al. Silicon transporter in rice. Nature, London, v. 440, n. 7084, p. 688-691, 2006.

MA, J. F.; YAMAJI, N. Silicon uptake and accumulation in higher plants. Trends in Plant Science, Amsterdam, v. 11, n. 8, p. 392-397, 2006.

MA, J. F.; SASAKI, M.; MATSUMOTO, H. Al-induced inhibition of root elongation in corn, Zea mays L., is overcome by Si addition. Plant and Soil, Dordrecht, v. 188, n. 2, p. 171-176, 1997.

MALAVOLTA, E.; VITTI, G. C.; OLIVEIRA, S. A. Avaliação do estado nutricional de plantas: princípio e aplicações. 2. ed. Piracicaba: Associação Brasileira para Pesquisa da Potassa e do Fosfato, 1997.

MARSCHNER, H. Mineral nutrition of higher plants. 2. ed. San Diego: Academic Press, 1995.

MAUAD, M. et al. Teores de silício no solo e na planta de arroz de terras altas com diferentes doses de adubação silicatada e nitrogenada. Revista Brasileira de Ciência do Solo, Viçosa, v. 27, n. 5, p. 867-873, 2003.

MENDONÇA, R. J. et al. Efeito do alumínio na absorção e na utilização de macronutrientes em duas cultivares de arroz. Pesquisa Agropecuária Brasileira, Brasília, DF, v. 38, n. 7, p. 843-846, 2003.

MITANI, K.; MA, J. F. Uptake system of silicon in different plant species. Journal of Experimental Botany, Oxford, v. 56, n. 414, p. 1255-1261, 2005.

NHAN, P. P.; HAI, N. T. Amelioration of aluminum toxicity on OM4900 rice seedlings by sodium silicate. African Journal of Plant Science, Ebène, v. 7, n. 6, p. 208212, 2013.

PRADO, R. M.; FERNANDES, F. M.; NATALE, W. Efeito residual da escória de siderurgia como corretivo da acidez do solo na soqueira da cana-de-açúcar. Revista Brasileira de Ciência do Solo, Viçosa, v. 27, n. 2, p. 287-296, 2003.

RAMOS, D. T. et al. Influência da adubação silicatada na produção de arroz de sequeiro. Revista Brasileira de Ciências Agrárias, Recife, v. 7, n. 4, p. 543-547, 2012.

REIS, M. A. et al. Aplicação de silício em arroz de terras altas irrigado por aspersão. Acta Scientiarum Agronomy, Maringá, v. 30, n. 1, p. 37-43, 2008.

RYDER, M. et al. The use of root growth and modeling data to investigate amelioration of aluminum toxicity by silicon in Picea abies seedlings. Journal of Inorganic Biochemistry, New York, v. 97, n. 1, p. 52-58, 2003.

SAVANT, N. K.; DATNOFF, L. E.; SNYDER, G. H. Depletion of plant-available silicon in soils: a possible cause of declining rice yields. Communications in Soil Science and Plant Analysis, New York, v. 28, n. 13-14, p. 1245-1252, 1997.
SILVA, L. M. et al. Sistema radicular de cultivares de arroz submetidas ao alumínio em solução nutritiva. Revista Agrarian, Dourados, v. 4, n. 13, p. 202-212, 2011.

SINGH, V. P. et al. Influence of exogenous silicon addition on aluminum tolerance in rice seedlings. Biological Trace Element Research, Totowa, v. 144, n. 1, p. 1260-1274, 2011.

SOUZA, D. M. G.; MIRANDA, L. N.; OLIVEIRA, S. A. Acidez do solo e sua correção. In: NOVAIS, R. F. et al. (Coords.). Fertilidade do solo. Viçosa: Sociedade Brasileira de Ciência do Solo, 2007. p. 205-274.

SUN, P. et al. Aluminum-induced inhibition of root elongation in Arabidopsis is mediated by ethylene and auxin. Journal of Experimental Botany, Oxford, v. 61, n. 2, p. 346-56, 2010.

TOKURA, A. M. et al. Dinâmica das formas de fósforo em solos de textura e mineralogia contrastantes cultivados com arroz. Acta Scientiarum Agronomy, Maringá, v. 33, n. 1, p. 171-179, 2011.

VIEIRA, S. Estatística experimental. 2. ed. São Paulo: Atlas, 1999.

WALLACE, A. Relationships among nitrogen, silicon, and heavy metal uptake by plants. Soil Science, The Hague, v. 147 , n. 6 , p. 457-460, 1989.

WANG, Y.; STASS, A.; HORST, W. J. Apoplastic binding of aluminum is involved in silicon-induced amelioration of aluminum toxicity in mayze. Plant Physiology, Bethesda, v. 136 , n. 6 , p. 3762-3770, 2004. 